\title{
Single-Incision Laparoscopic Surgery in Urology
}

\author{
Hammouda Sherif Magdy El-Tabey Ahmed Abo-taleb Ahmed Abdelbaky \\ Urology Department, Faculty of Medicine, Benha University, Benha, Egypt
}

\begin{abstract}
Key Words
Single-incision laparoscopic surgery • Laparoscopy •

Renal cyst • Nephrectomy • Pyelolithotomy •

Varicocelectomy $\cdot$ Orchiopexy
\end{abstract}

\begin{abstract}
Introduction: To assess the feasibility of single-incision laparoscopic surgery (SILS) in some urological surgeries. Material and Methods: This prospective study was conducted on 40 patients ( 27 males and 13 females) from January 2010 to June 2011. Six procedures were done, SILS renal cyst decortication $(n=10)$, SILS varicocelectomy $(n=10)$, SILS orchiopexy $(n=10)$, SILS nephrectomy $(n=3)$, SILS pyelolithtomy $(n=6)$ and SILS adrenalectomy $(n=1)$. Results: Postoperative complications included ileus (10\%) and fever (10\%) in SILS renal cyst ablation. SILS varicocelectomy had postoperative sequalae as persistent varicocele (10\%) and hydrocele (10\%). SILS orchiopexy was also done with a success rate $100 \%$ in this series. SILS pyelolithotomy was successfully done in 5 out of 6 patients and only 1 patient was converted to conventional laparoscopy. In SILS nephrectomy 1 patient out of 3 was converted to conventional laparoscopy. Conclusion: SILS in urology has proven to be safe and feasible in the hands of experienced laparoscopic surgeons, using specially designed ports and instruments in selected patients.

Copyright $\odot 2012$ S. Karger AG, Basel
\end{abstract}

\section{Introduction}

Single-incision laparoscopic surgery (SILS) represents a progression in laparoscopic surgery and is being reported with increasing frequency [1]. It appears as though this technique may have promise compared to its conventional laparoscopic counterpart in terms of operative outcomes, postoperative pain, length of hospitalization, and patient reported convalescence after certain procedures [2].

SILS access can be obtained either by performing a single skin and facial incision through which a single multi-channel access platform is placed (single-port) or by placing several low profile ports (single-site). Rane el al. [3] first reported the urological use of a single multifunctional port while the first multi-trocar single-incision transumbilical nephrectomy was by Raman et al. [4]. Since then, several other clinical series have been reported, and the entire spectrum of urological procedures both for upper and lower urinary tract diseases has been described and shown to be feasible [5]. Despite representing an evolution of standard laparoscopy, SILS defies the most basic laparoscopic concepts, including triangulation of working instruments and external spacing to decrease clashing. Thus, the transition from standard laparoscopy to SILS has represented a major paradigm shift. To overcome technical limitations related to SILS, industries have also developed a new generation of purpose-built optics and instruments [6].

Articulating instruments have been conceptually developed to allow the surgeon's hands to be positioned farther apart while some triangulation is internally created. A recognized issue that is related to these new devices is cost. In general, the use of disposable instruments increases the cost of laparoscopic procedures, and the same is likely to happen for SILS [6].

In the current study, we present our technique for SILS in urological surgery and present our experience with 40 cases.

\section{KARGER}

Fax +4161306 1234

E-Mail karger@karger.ch

www.karger.com
(C) 2012 S. Karger AG, Basel

$1015-9770 / 12 / 0061-0008 \$ 26.00 / 0$

Accessible online at:

www.karger.com/cur
Hammouda Sherif

10 Elashraf Street, Benha Elgdeeda

Benha (Egypt)

Tel: +201222904225, Fax +20133220100, E-Mail hammoda_elsherif@yahoo.com 

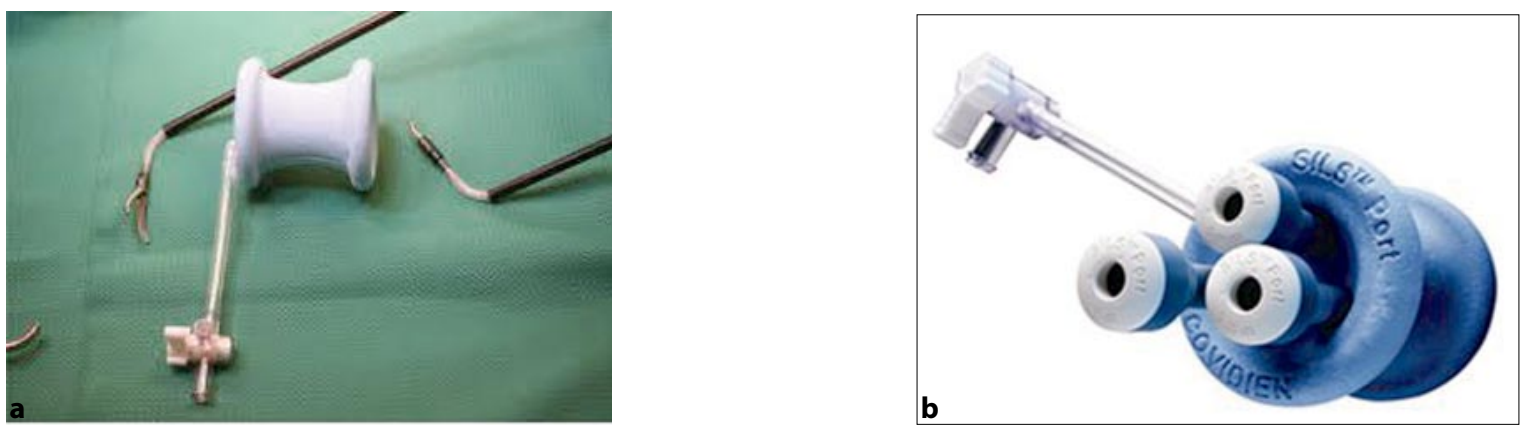

Fig. 1. a SILS port and $5 \mathrm{~mm}$ articulating instruments; b SILS port.

\section{Patients and Methods}

This prospective study was conducted on 40 patients ( 27 males and 13 females) who were selected and admitted to Urology Department, Benha University Hospital from January 2010 to June 2011. Exclusion criteria included recurrent upper urinary tract surgery, previous multiple abdominal operations, uncorrected coagulopathy, severe cardiopulmonary diseases and history of peritonitis. All patients were subjected to complete history taking, physical examination and routine laboratory and radiological investigations.

Informed written consent was taken from all participants concerning the procedure, possibility for conversion to conventional laparoscopy (CL) or open surgery. The study protocol was approved by the research ethical committee of Benha Faculty of Medicine.

\section{Operative Setup}

Under standard general anesthesia with endotracheal tube intubation, bladder catheterization, and orogastric tube placement.

\section{Laparoscopic Instrument}

The SILS device from Covidien contains 4 openings, 1 for insufflation via a right angled tube and 3 that can accommodate 5-12 $\mathrm{mm}$ in size. The compressibility of the elastic polymer allows the access ports to expand and form fit the space in which they reside as will the ports through the working channels (fig. 1A, 1B).

Articulating instruments include $5 \mathrm{~mm}$ roticulator dissector and $5 \mathrm{~mm}$ roticulator electrosurgical scissor. Conventional laparoscopic instruments were prepared on the table.

\section{Technique}

Using the transumbilical open Hasson technique, a 2-2.5 cm vertical intraumbilical skin incision was made. Two tissue forceps were placed to evert both edges of the incision. A vertical midline anterior rectus fasciotomy was made, the abdominal cavity was entered, and a sweep of the finger verified lack of underlying adhesions. The lower edge of the SILS port was grasped via curved artery forceps, and then a lubricant was placed. The port was then deployed and secured in place. The $12 \mathrm{~mm}$ cannula was placed by its obturator followed by the two $5 \mathrm{~mm}$ cannulas. These cannulas (ports) were placed at different heights to reduce instruments clashing. The port had an insufflation channel which was connected to the insufflation line to achieve $\mathrm{CO}_{2}$ pneumoperitoneum to a pressure of $15 \mathrm{mmHg}$. A $10 \mathrm{~mm} \mathrm{0-degree} \mathrm{lens} \mathrm{was} \mathrm{introduced}$ through the $12 \mathrm{~mm}$ cannula for inspection of the abdominal cavity, followed by the articulating instruments.

\section{SILS Renal Cyst Decortication}

A total of 10 patients ( 2 males and 8 females) were subjected to SILS ablation of symptomatic renal cysts.

Operative Procedure The patients were placed in the 45-degree flank position with the operating table minimally flexed. The SILS port was introduced as before and then the operating table was tilted towards the surgeon to retract the bowel away from the kidney. Reflection of the colon medially was created after incision in the posterior peritoneum. Gerota's fascia and perirenal fat were carefully dissected to show the blue dome appearance of the cyst (fig. 2) and then the procedure was completed similar to those of conventional laparoscopic cyst ablation without additional extraumbilical ports.

\section{SILS Nephrectomy}

Two out of 3 patients who underwent SILS nephrectomy had loin pain from a non-functioning kidney while the other had persistent hypertension caused also by a non-functioning hypoplastic kidney.

Operative Procedure As before the procedure was completed similar to those of conventional laparoscopic nephrectomy without additional extraumbilical ports.

The renal artery was secured by 3 endoclips ( 2 proximal and 1 distal) (fig. 3). The renal vein was secured by an Endo-GIA stapler, and then they were sealed by $5 \mathrm{~mm}$ LigaSure (fig. 4). In the case of the hydronephrosis it was grasped by an Endo Babcock and totally extracted by gentle gradual traction on renal tissue 


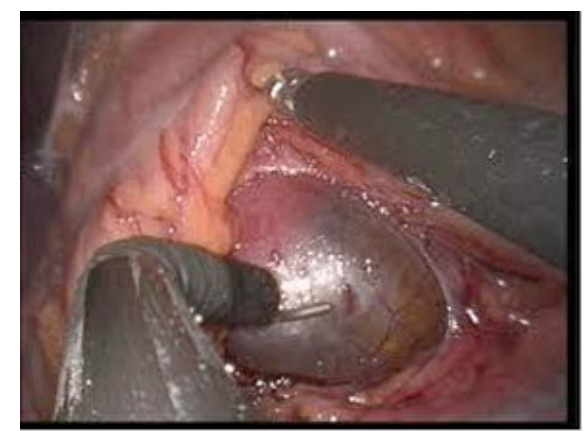

Fig. 2. Blue dome appearance of the renal cyst.

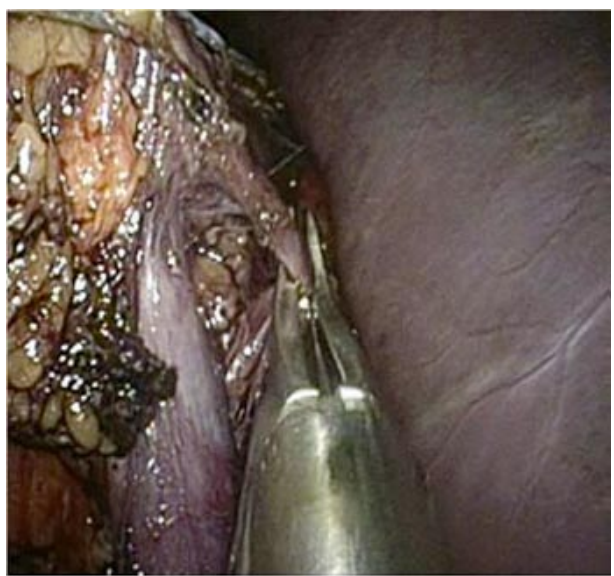

Fig. 3. Ligation of the renal artery.

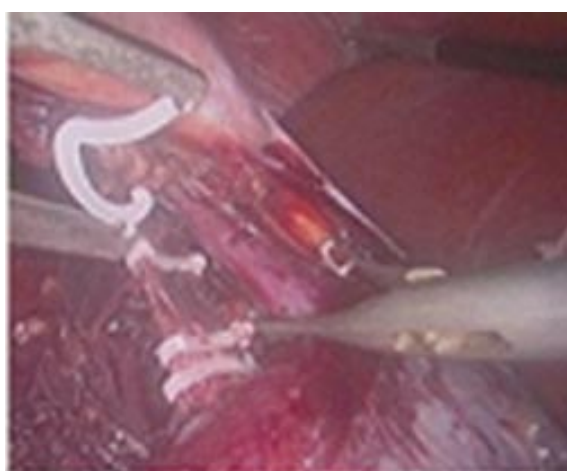

Fig. 4. Securing the renal vein by endoclips. through the umbilical incision while removing the SILS port at the same time. The hypoplastic kidney was also removed through the umbilical incision without a laparoscopic sac.

\section{SILS Pyelolithotomy}

Six patients that underwent pyelolithotomy had pelvic stones in an ectopic kidney.

Operative Procedure The patients were initially placed in the lithotomy position and a retrograde ureteropyelogram and stent placement were carried out. The patients were placed in the 30degree position. The stone was easily identified by the use of fluoroscopy. A $3 \mathrm{~cm}$ pyelotomy was made in the anterior surface of the renal pelvis. The $10 \mathrm{~mm}$ biopsy forceps were introduced through the pyelotomy and the stone was extracted. Then the pyelotomy was closed via 2-0 polysorp suture.

\section{SILS Adrenalectomy}

One 35-year-old patient was subjected to SILS right adrenalectomy. A CT guided biopsy was taken, and histopathology revealed adenoma of the adrenal gland. The patient was placed in the 45-degree flank position with the operating table minimally flexed.

Creation of pneumoperitoneum and introduction of instrumentations were made by incision on the peritoneal reflection along the liver edge for the right adrenal lesion. Once the adrenal vein and adrenal arteries were secured, the adrenal gland was mobilized from the upper pole of the kidney with hook cautery, coagulating scissors, or ultrasonic scissors. After adrenalectomy, the laparoscopic bag was placed through the camera port and then the specimen was extracted.

\section{SILS Varicocelectomy}

A total of 10 patients underwent SILS varicocelectomy, eight of them were complaining of infertility for more than 1 year, while 2 patients were complaining of testicular pain. Nine patients underwent bilateral varicocelectomy while 1 patient underwent unilateral varicocelectomy. Preoperative investigations included semen analysis, with scrotal ultrasound. The patients were placed in the supine position. The pelvis was inspected and the main landmarks were identified including the gonadal vessels proximal to the internal inguinal ring and the vas differentia.

Articulating laparoscopic graspers and scissors were introduced through the SILS port, and then an incision was made in the posterior peritoneum medial and lateral to the testicular artery and vein proximal to the vas deference. The testicular vessels were dissected from the lymphatics and then endoclips were placed both proximally and distally in the pedicle in the dissected region to both artery and vein.

\section{SILS Orchiopexy}

In this group 10 male patients were subjected to single port transumbilical laparoscopic orchiopexy. Six patients had a nonpalpable left testis $(60 \%)$ while 4 had a nonpalpable right testis (40\%). Preoperative investigations included pelvi-abdominal ultrasound, and MRI to locate the nonpalpable testis. The patients were placed in the supine position. After inspection of the abdomen by diagnostic laparoscopy it was found that 9 of the 10 patients had a high intra-abdominal testis less than $2 \mathrm{~cm}$ from the internal ring, while 1 patient had an inguinal testis. The internal ring was marked by the confluence of the vas deferens (medial) 
and the spermatic vessels (lateral). The spermatic vessels came into view just beneath the ipsilateral colonic flexure which led to the location of the testis. The peritoneum was opened lateral to the spermatic vessels, and the testicular vessels and the vas deferens were mobilized in the retro peritoneum. Through a small scrotal incision a dartos pouch was created. A 5-mm port was placed in a tunnel from the scrotum into the external inguinal ring and through the abdominal wall into the peritoneal cavity lateral to the inferior epigastric vessels. A grasper was inserted through the port to pull the remnant of the gubernaculum down. The testicle was then fixed to the scrotum in the dartos pouch in the usual fashion.

\section{Statistical Analysis}

The collected data were tabulated and analyzed by using Statistical Package of Social Science (SPSS) version 16 software. Suitable statistical techniques were computed (frequencies, mean, standard deviation and range).

\section{Results}

A total of 6 procedures including 10 patients underwent SILS renal cyst decortications, 10 patients underwent SILS varicocelectomy, 10 patients underwent SILS orchiopexy, 3 patients underwent SILS nephrectomy, 6 patients underwent SILS pyelolithtomy, and 1 patient underwent SILS adrenalectomy. Table 1 shows preoperative patients demographics. Intra- and post-operative data is reported in table 2 while table 3 shows postoperative visual analogue scale (VAS), the number of patients who needed postoperative analgesics of diclofinac sodium $(75-150 \mathrm{mg})$, and the VAS is the range of postoperative pain (mean \pm SD), VAS in children who had SILS orchiopexy performed was stated by their mothers.

No drain was needed in SILS varicocelectomy and SILS orchiopexy. The drain was removed in the patient who had SILS adrenalectomy performed after 2 days. It was removed in patients who underwent SILS renal cyst decortications within $2.4 \pm 0.51$ days (range 2-3 days) while $2.6 \pm 0.57$ days (range $2-3$ days) in patients who underwent SILS nephrectomy, also it was removed in patients who underwent SILS pyelolithotomy 3.6 \pm 0.51 days (range 3-4 days).

Two patients who underwent SILS renal cyst decortication had immediate postoperative complications, 1 with prolonged ileus and the other with prolonged fever. Two patients who underwent SILS varicocelectomy had postoperative complications, 1 patient had postoperative hydrocele and the other had recurrent varicocele.

Significant correlation was seen as regard preoperative and postoperative results of semen analysis in the

Single-Incision Laparoscopic Surgery in Urology patients who underwent SILS varicocelectomy. The mean preoperative spermatic density was $12.58 \pm 2.52$ $\times 10^{6} / \mathrm{ml}$ (range $9-17.6 \times 10^{6} / \mathrm{ml}$ ), while the mean spermatic motility was $28.8 \pm 7.92 \%$ (range $20-40 \%$ ). Postoperative 6 months follow-up semen analysis showed that the mean postoperative sperm density was $20.34 \pm$ $1.5 \times 10^{6} / \mathrm{ml}$ (range $18.4-23 \times 10^{6} / \mathrm{ml}$ ), while the mean postoperative sperm motility was $45.89 \pm 8.37 \%$ (range $33-60 \%)(\mathrm{p}<0.05)$.

\section{Discussion}

Single port laparoscopic surgery was introduced as a further development of laparoscopy. Nevertheless, wide spread acceptance of this technique requires adequate documentation of the advantages of this approach over $\mathrm{CL}$ and further refinement of surgical instrumentation to minimize intra- and post-operative problems [7]. Laparoendoscopic single site (LESS) surgery creates a challenge for surgeons to increase their skills and experience [8].

In our study, SILS renal cyst ablation was carried out without intraoperative complications and no patient was converted to CL. Prolonged ileus occurred in 1 patient $(10 \%)$ and fever in another, but these were resolved with conservative management and no infected port site was seen. Our results can be compared with reports of White et al. [9] in a single port urological surgery including renal cyst decortication where they found that the mean length of hospitalization was 3 days and the mean estimated blood loss (EBL) was $165 \mathrm{ml}$. No intraoperative complications occurred. In another study by Ryu et al. [10] LESS surgery in urology including renal cyst ablation, all cases were completed without conversion to CL or open surgery. The mean operative time and mean EBL for SILS renal cyst decortication were 85 minutes (range 75-100 minutes) and the EBL was $179 \mathrm{ml}$ (range 22-398 $\mathrm{ml})$, respectively.

However, reports that compared the standard laparoscopic ablation of renal cyst to SILS renal cyst decortication showed that the measures of in-hospital morbidity were equivalent. LESS shortens convalescence as measured by VAS and by pain medications required after discharge. It seems an attractive alternative as it combines the advantages of minimally invasive procedure with effectiveness of cyst marsupealization [6].

In this study, 3 patients underwent SILS nephrectomy for benign lesions. One case was converted to CL due to severe adhesions that resulted from chronic pyelone- 
Table 1. Patients' preoperative demographics

\begin{tabular}{lllll}
\hline & Age, years & Weight, $\mathrm{kg}$ & Height, $\mathrm{m}$ & BMI, kg/m ${ }^{2}$ \\
\hline SILS renal cyst decortications $(\mathrm{n}=10)$ & $43.9(24-56)$ & $89.1(59-105)$ & $1.7(1.55-1.82)$ & $31.21(19.37-41.66)$ \\
SILS varicocelectomy $(\mathrm{n}=10)$ & $25(16-44)$ & $77(65-95)$ & $1.74(1.4-1.9)$ & $24.01(20.56-26.64)$ \\
SILS orchiopexy $(\mathrm{n}=10)$ & $3.9(1-8)$ & $16.5(11-23)$ & $1.25(0.8-1.6)$ & $16.44(6.37-24.32)$ \\
SILS nephrectomy $(\mathrm{n}=3)$ & $54.3(44-60)$ & $96.6(88-110)$ & $1.7(1.66-1.8)$ & $32.17(27.1-35.9)$ \\
SILS pyelolithotomy $(\mathrm{n}=6)$ & $46(33-55)$ & $90.5(85-101)$ & $1.77(1.7-1.88)$ & $29.01(26.34-33.77)$ \\
SILS adrenalectomy $(\mathrm{n}=1)$ & 35 & 80 & 1.78 & 25.31 \\
\hline
\end{tabular}

Table 2. Intra- and post-operative data

\begin{tabular}{lllll}
\hline & Operative time, minutes & Blood loss, $\mathrm{ml}$ & Oral feeding, $\mathrm{d}$ & Hospital stay, $\mathrm{d}$ \\
\hline SILS renal cyst decortications $(\mathrm{n}=10)$ & $90.4(80-100)$ & $86.4(30-130)$ & $1.3(1-2)$ & $2.9(2-4)$ \\
SILS varicocelectomy $(\mathrm{n}=10)$ & $64.6(52-100)$ & $51.9(30-70)$ & $0.55(0.5-1)$ & $1.6(1-2)$ \\
SILS orchiopexy $(\mathrm{n}=10)$ & $55.8(44-90)$ & $14.2(10-22)$ & $0.55(0.5-1)$ & $1.05(1-1.5)$ \\
SILS nephrectomy $(\mathrm{n}=3)$ & $138.33(100-160)$ & $120(100-150)$ & $2(1-3)$ & $3.6(3-4)$ \\
SILS pyelolithotomy $(\mathrm{n}=6)$ & $110(60-200)$ & $130.16(100-150)$ & $2(1-4)$ & $3.5(3-5)$ \\
SILS adrenalectomy $(\mathrm{n}=1)$ & 200 & 120 & 1 & 5 \\
\hline
\end{tabular}

Table 3. Postoperative VAS

\begin{tabular}{llll}
\hline & VAS & Patients needing postoperative analgesics & Return to normal activity, d \\
\hline SILS renal cyst decortications $(\mathrm{n}=10)$ & $2.4(1.5-5)$ & 1 & $4.9(4-6)$ \\
SILS varicocelectomy $(\mathrm{n}=10)$ & $1.49(1.2-2)$ & 0 & $4.4(4-6)$ \\
SILS orchiopexy $(\mathrm{n}=10)$ & $1.13(1-1.3)$ & 0 & $4.3(4-5)$ \\
SILS nephrectomy $(\mathrm{n}=3)$ & $5(2-8)$ & 1 & $7.3(4-10)$ \\
SILS pyelolithotomy $(\mathrm{n}=6)$ & $3.83(2.7-6)$ & 1 & $7(5-10)$ \\
SILS adrenalectomy $(\mathrm{n}=1)$ & 4 & 1 & 7
\end{tabular}

phritis. An immediate postoperative complication was noticed in 1 patient with prolonged ileus which was resolved with conservative measures.

Similar results were reported by Raman et al. [4] who successfully performed the first multi-trocar single incision transumbilical nephrectomy with a mean operative time of 133 minutes. In another study, a simple nephrectomy was performed in over 3 hours without need for any other incisions using R-port and special curved laparoscopic graspers [11].

There were 2 large urological SILS series of 200 procedures, and they reported 23 nephrectomies, 14 of them were simple in which the mean operative time was 145 minutes and the EBL was $109 \mathrm{ml}$ [11]. The other study was performed by White et al. [9] who performed 28 nephrectomies, 7 of which were simple. The mean operative time was 156 minutes and the EBL was $121 \mathrm{ml}$.

In this study patients underwent SILS pyelolithotomy, the stones were successfully removed by SILS in 5 patients, and 1 patient was converted to CL due to severe adhesions due to pyelonephritic changes. Casale et al. [12] performed 7 laparoscopic pyelolithotomies with a mean operative time of 197 minutes. The average length of hospital stay was 3 days which was similar to our re- 
sults and also no major complications were documented. Stones were completely removed in 6 patients, while the seventh had clinically insignificant fragments $(<4 \mathrm{~mm})$. No strictures developed on intra-venous urography follow-up. Despite its high median stone-free rate, open surgery is not longer recommended as a first line treatment for pelvic and ureteric stones, because of longer hospitalization and greater postoperative morbidity. Laparoscopic surgery is preferable because of its decreased invasiveness and resultant reduced morbidity and has been well described in this setting [13].

In another study LESS was performed by Desai et al. [14] with a mean operative time and EBL of 236 minutes and $79 \mathrm{ml}$, respectively. There were no complications, but all cases required an additional 2-mm port. One case was converted to CL. All patients were symptom-free and postoperative imaging showed unobstructed drainage in 15 of the 16 patients for whom data were available. LESS has given good outcomes, because of the importance of cosmosis in young patients and the ability to deal with crossing vessels and concomitant stones at the time of surgery.

Attempts to perform SILS adrenalectomy began with a report by Hirano et al. [15]. The investigators used a specialized resectoscope tube with a 4-cm diameter and standard laparoscopic instruments to perform a retroperitonescopic adrenalectomy. The average operating time was 203 minutes and the mean EBL was $252 \mathrm{ml}$. Single port laparoscopic transabdominal adrenalectomy has been performed successfully since 2008. Desai et al. [11] reported mean operative time of 2 hours, with EBL of $10-150 \mathrm{ml}$ and mean length of hospital stay 2.2 days. All these results are comparable to our case study.

As regards SILS varicocelectomy there were significant correlations detected as regard pre- and post-operative results of semen analysis, also there were no intraoperative complications. In a group of 23 patients who underwent laparoscopic varicocelectomy, the operative time was 70 minutes (range 50-82 minutes), the mean hospital stay was 2 days, no intraoperative complications and no conversion to open surgery occurred [16]. Rabah et al. [17] stated that the mean hospital stay was 1.2 days, also at 6 months follow-up hydrocele was reported in 2 patients $(5 \%)$ and persistent varicocele in 1 patient $(2.5 \%)$.

The relatively higher incidence of postoperative complications of open varicocelectomy may be explained by the fact that this method involves mass transection of testicular vessels in the retroperitoneum above the internal inguinal ring with lymphatic obstruction [18]. Moreover, single port surgery gives the advantage of reducing the number of abdominal incisions to one that can be hidden in the umbilicus. This renders the surgery virtually scar-less as the additional two ports are not required. The introduction of flexible instruments provides superior maneuverability especially when instruments are introduced parallel through one umbilical incision. However, clashing of instruments and the laparoscope is common and thus significant coordination between the surgeon and the camera holder is essential [16].

All patients who underwent SILS orchiopexy were done in one stage with a success rate $100 \%$ in this study. In a comparative study, de Lima et al. [19] reported that SILS orchiopexy had an operative time of 1.5 hours with minimal blood loss and the patient was discharged after 24 hours. The reported success rate for laparoscopic orchiopexy of intra-abdominal testicles has far exceeded that of open repair (95 vs. $76 \%$ ). It was believed that minimal manipulation of the testicles during dissection, a wider peritoneal window, and sparse use of electrocautery resulted in adequate testicular position even for high intra-abdominal gonads with minimal risk of atrophy [20].

Rane et al. [3] reported that orchiopexy and orchidectomy had been successfully done through a single incision without complications. SILS orchiopexy has become a part of urological applications of single site laparoscopic surgery [21].

\section{Conclusion}

SILS in urology has proved to be safe and feasible in the hands of experienced laparoscopic surgeons, using specially designed ports and instruments in selected patients. It offers the advantages of reducing the number of abdominal incisions to one that can be hidden in the umbilicus, less post-operative pain, early ambulation, shorter hospitalization, convalescence and improved cosmoses.

\section{Acknowledgements}

The authors are grateful to the residents in Urology Department, Benha University Hospital, Benha, Egypt for help in patients' recruitment and follow-up. 


\section{References}

-1 Gettman MT, Box G, Averch T, Cadeddu JA, Cherullo E, Clayman RV, Desai M, Frank I, Gill I, Gupta M, Haber GP, Humphreys M, Kaouk J, Landman J, Lima E, Ponsky L: Consensus statement on natural orifice transluminal endoscopic surgery and single-incision laparoscopic surgery: heralding a new era in urology? Eur Urol 2008;53:1117-1120.

2 Tugcu V, Ilbey YO, Mutlu B, Tasci AI: Laparoendoscopic single-site surgery versus standard laparoscopic simple nephrectomy: a prospective randomized study. J Endourol 2010;24:1315-1320.

3 Rane A, Rao P, Rao P: Single-port-access nephrectomy and other laparoscopic urologic procedures using a novel laparoscopic port (R-port). Urology 2008;72:260-264.

4 Raman JD, Bensalah K, Bagrodia A, Stern JM, Cadeddu JA: Laboratory and clinical development of single keyhole umbilical nephrectomy. Urology 2007;70:1039-1042.

-5 Autorino R, Stein RJ, Lima E, Damiano R, Khanna R, Haber GP, White MA, Kaouk JH: Current status and future perspectives in laparoendoscopic single-site and natural orifice transluminal endoscopic urological surgery. Int J Urol 2010;17:410-431.

6 Kommu SS, Rane A: Devices for laparoendoscopic single-site surgery in urology. Expert Rev Med Devices 2009;6:95-103.

7 Tracy CR, Raman JD, Cadeddu JA, Rane A: Laparoscopic single-site surgery in urology: where have we been and where are we heading? Nat Clin Pract Urol 2008;5:561-568.
-8 Raman JD, Bagrodia A, Cadeddu JA: Single-incision umbilical laparoscopic versus conventional laparoscopic nephrectomey: a comparison of perioperative outcomes and short-term measures of convalescence. Eur Urol 2009;55:1198-1204.

\$9 White WM, Haber GP, Goel RK, Crouzet S, Stein RJ, Kaouk JH: Single-port urological surgery: single-center experience with the first 100 cases. Urology 2009;74:801-804.

10 Ryu DS, Park WJ, Oh TH: Retroperitoneal laparoendoscopic single-site surgery in urology: initial experience. J Endourol 2009;23: 1857-1862.

11 Desai MM, Rao PP, Aron M, Pascal-Haber G, Desai MR, Mishra s, Kaouk JH, Gill IS: Scarless single port transumbilical nephrectomy and pyeloplasty: first clinical report. BJU Int 2008;101:83-88.

12 Casale P, Grady RW, Joyner BD, Zeltser IS, Kuo RL, Mitchell ME: Transperitoneal laparoscopic pyelolithotomy after failed percutaneous access in the pediatric patient. J Urol 2004;172:680-683.

13 Goel A, Hemal A: Laparoscopic radical nephrectomy: is it ontologically safe? Indian J Urol 2003;20:1-6.

14 Desai MM, Berger AK, Brandina R, Aron M, Irwin BH, Canes D, Desai MR, Rao PP, Sotelo R, Stein R, Gill IS: Laparoendoscopic single-site surgery: initial hundred patients. Urology 2009;74:805-812.
15 Hirano D, Minei S, Yamaguchi K, Yoshikawa $T$, Hachiya $T$, Yoshida $T$, Ishida $H$, Takimoto Y, Saitoh T, Kiyotaki S, Okada K: Retroperitoneoscopic adrenalectomy for adrenal tumors via a single large port. J Endourol 2005;19:788-792.

16 Kaouk JH, Haber GP, Goel RK, Desai MM, Aron M, Rackley RR, Moore C, Gill IS: Single-port laparoscopic surgery in urology: initial experience. Urology 2008;71:3-6.

17 Rabah DM, Adwan AA, Seid MA: Lymphatic preservation using methylene blue dye during laparoscopic varicocelectomy: early results. Can J Urol 2009;16:4826-4830.

18 Hassan JM, Adams MC, Pop JC 4th, Demarco RT, Brock JW 3rd: Hydrocele formation following laparoscopic varicocelectomy. J Urol 2006;175:1076-1079.

19 De Lima GR, da Silveira RA, de Cerqueira JB, de Abreu AC, de Abreu Filho AC, Rocha MF, Regadas RP, Gonzaga-Silva LF: Singleincision multiport laparoscopic orchidopexy: initial report. J Pediatr Surg 2009;44:2054 2056.

20 Samadi AA, Palmer LS, Franco I: Laparoscopic orchiopexy: report of 203 cases with review of diagnosis, operative technique, and lessons learned. J Endourol 2003;17:365368.

21 Symes A, Rane A: Urologic applications of single-site laparoscopic surgery. J Minim Access Surg 2011;7:90-95. 